\title{
Relationship between Romantic Love, Narcissism, and Subjective Well-Being
}

\author{
Trương Thi Khanh Ha*, Nguyen Huy Hoang, Pham Thi Yen \\ Faculty of Psychology, University of Social Sciences and Humanities, Vietnam National University (VNU-Hanoi), Hanoi, \\ Vietnam \\ Email: *ttkha@vnu.edu.vn
}

How to cite this paper: Ha, T.T.K., Hoang, N.H. and Yen, P.T. (2018) Relationship between Romantic Love, Narcissism, and Subjective Well-Being. Open Journal of Social Sciences, 6, 183-197. https://doi.org/10.4236/jss.2018.69013

Received: August 23, 2018

Accepted: September 11, 2018

Published: September 14, 2018

Copyright (c) 2018 by authors and Scientific Research Publishing Inc. This work is licensed under the Creative Commons Attribution International License (CC BY 4.0).

http://creativecommons.org/licenses/by/4.0/

(c) (i) Open Access

\begin{abstract}
Love could be one of the factors affecting on human happiness. Love (love others) and narcissism (self-love) could have a special relationship. This study aims to analyze the relationship between Love, Subjective well-being, and Narcissism, taking into account some of the cultural characteristics of Vietnam. The survey was conducted on 543 people aged from 19 to 40 years $(\mathrm{M}=$ 27.8; SD $=6.5$ ), included 369 women $(67.5 \%), 251$ married people $(46 \%)$. Love was measured using the Sternberg Love Scale [11]; Subjective well-being were measured by the Mental Health Continuum-Short Form [15]; Agentic narcissism was measured by the Narcissistic Personality Inventory [6]. The marital status was included in the study for comparison purpose. The results showed that Love and Narcissism do not have the significant correlation, while Love and Narcissism were positively correlated to the Subjective well-being. These positive correlations were higher among the married people. On average, Narcissism of married people was lower, while Love and Subjective well-being of married people was higher than that of the unmarried people. The paper also discusses about the positive correlation between subjective well-being and narcissism, and the positive effect of marriage on love and happiness of Vietnamese people.
\end{abstract}

\section{Keywords}

Narcissism, Love, Subjective Well-Being, Vietnamese

\section{Introduction}

The term "narcissism" comes from the Greek myth of Narcissus, which describes a conflict between self-love and love for another person. Fundamental psychological expressions of narcissism are related to core characteristics like a grandiose self-perception, a lack of sympathy for others, and the need for respect. In 
the conventional thinking of those living in a collectivistic culture like Vietnam, narcissism is understood as selfishness-a character trait which is harshly criticized. Individuals living in the contexts of family, school, at the workplace usually find a way to eliminate the existence of narcissism (for instance, through suggestions, criticizing those who express arrogant or authoritative thoughts, wear sexually attractive or swanky clothing, refuse to be depend on others, or asking for personal benefits), because they felt that these expressions are immodest, anti-social, individualistic, and put personal interests ahead of public interests. As mentioned, whereas narcissism focuses on the self, romantic love focuses on another person. The questions for psychologists is how narcissism (self-love) and romantic love (love of someone else) are related to each other, and how both of these terms affected individual's well-being.

Previous research, including by this author, has shown that love has a positive impact on individual's well-being [1]. The impact of narcissism on well-being has been studied within Western society, showing that narcissism has a positive relationship with well-being [2] [3]. However, it is hypothesized here that in a collectivistic culture like Vietnam, narcissism may have a negative relationship with well-being. Furthermore, it is hypothesized that romantic love (love of someone else) and narcissism (self-love) may have a negative correlation with each other, and love will have a positive relationship with an individual's well-being.

\section{Literature Review}

\subsection{Narcissism}

Narcissism can be categorized in many ways. Based on the level analysed, there is non-pathological narcissism (normal narcissism) and pathological narcissism. Based on phenotype, there is grandiose narcissism and vulnerable narcissism. Based on expression, there is overt narcissism and covert narcissism [4]. In this study, we consider narcissism as non-pathological narcissism involving a grandiose self-view.

From a social psychological approach, narcissism is viewed as a personal trait, which exists in all nonclinical populations. Both Catell (1957, cited according to [5]) and Fromm (1973, cited according to [5]) have pointed out the positive aspects of narcissism. They argued that a narcissistic self-perception about personal values and self-efficacy is necessary. Fischer (1984, cited according to [5]) also found that highly narcissistic individuals have a more positive character than people who have low levels of narcissism.

Nonpathological narcissism is defined as a way in which am individual uses subjective and objective factors to maintain a positive self-image. In order to maintain a positive self-image, an individual has to uses coping strategies and techniques to coordinate cognitive, emotional and behavioral processes. Many researchers have argued that people need to have some narcissistic traits and needs in the personal adaptation processes, however, when a narcissism trait is 
strongly expressed, according to DSM-V criteria, it becomes an expression of pathological narcissism [4].

Therefore, extremely high narcissism can turn into pathological narcissism. However, if narcissism only stops at highly self-evaluated personal contributions and achievements, to maintain a positive self-image, it would become the necessary characteristics for social adaptation processes.

In this paper, in order to examine narcissism as a personality trait, a Narcissistic Personality Inventory (NPI) [6], has been used positive self-view, sense of entitlement, and desire for power and esteem. The NPI can be considered as the most widespread tool to measure narcissism as a personality trait in a nonclinical population [5]. We can only identify someone as having Narcissistic Personality Disorder when they have extremely high NPI scores [6].

\subsection{Romantic Love}

Perhaps many would agree that romantic love is one of the most important relationships to adults.

Since ancient times, many philosophers have questioned the nature of romantic love and tried to interpret it. However, only at the end of the twentieth century, did psychologists focus on romantic love; attempting to discover its structure and the way of measuring this complex psychological phenomenon. One of the first psychological studies which sought to construct a measurement of love is [7] romantic love scale used in this study. Hitherto, there have been a variety of studies concerning about the parameters romantic love as well as developing the means to measure it [8] [9] [10].

Perspectives related to the components of romantic love differ. According to Sternberg [9], "Love is a complex whole that appears to derive in part from genetically transmitted instincts and drives, but probably is also to the extent derived from socially learned role modeling that, through observation, comes to be defined as love."

In analyzing this complex whole, he suggested a tripolar: intimacy, passion and decision/commitment. Specifically, the intimacy component is understood as feelings of closeness, bondedness, profound understanding and mutual support. The passion component refers to physical attractiveness and sexual intimacy. This component arouses drives that lead to infatuation in a loving relationship. The decision/commitment component is viewed as the decision to love another in the short-term and the commitment to maintain this romantic relationship in the long-term.

All three components are essential in the loving relationship, even though they are different in the role they perform and vary across time in the sense of mutually contributing to the romantic love whole. The combinations of these three components in a variety of ways can create different kinds of love [11]. In this study, we adopt the viewpoint of love triangle theory and use Sternberg's love scale to measure three components of the romantic relationship. 


\subsection{Well-Being}

Though there are many ways of understanding Well-being, most of the researchers agree that Well-being means one feels joyful about his/her life. According to Diener and colleagues [12], Well-being is individual's cognitive and emotional judgment about his/her life. People with high level of Well-being are those who are satisfied with their lives, usually have positive emotions and rarely have a negative emotion.

However, other author does not emphasize present emotions but pay more attention to meanings of life, self-fulfillment, and self-potential actualization. Accordingly, Ryff [13] suggested the 6-factor-model of Well-being, includes: autonomy, personal growth, self-acceptance, life purpose, mastery and positive relating.

However, Keyes [14] claimed that individuals live in society, thereby Well-being of an individual is strongly tied to his/her social surroundings in term of satisfaction with interpersonal relationships, with the community and the social environment his/her belongs to.

During together these interpretations with an integrated view, some authors proposed a three-factor approach to Well-being, encompassing: emotional well-being, psychological well-being, and social well-being. Keyes claimed that Well-being has a close relation to mental health, and mental health is a typical characteristic of Well-being [14] [15].

According to this view, the Mental Health Continuum-MHC was developed to assess the degree of the salience of three components constituting Well-being whole. Emotional well-being refers to positive emotional statuses about life. Psychological well-being might be understood in terms of self-acceptance, satisfaction with almost all aspects of oneself, having warm and trustful relationships, having the strong belief that one can become better, having a purpose in life purpose, being able to be self-autonomous and self-making decision [16]. Social Well-being presents satisfaction to the social circle, acceptance to almost of what society is, feeling of belonging to the community with being accepted and seeing oneself as a meaningful contributor to society [14].

We choose this integrated view and use Keyes's scale to measure three factors of Well-being in our study.

\section{Method}

\subsection{Samples}

543 participants aged between 19 to 40 years old $(\mathrm{M}=27.8$; $\mathrm{SD}=6.5)$ with 369 females (67.5\%), 174 males (32.5\%). 251 participants were in marriage relationship (46\%). Gender and marital status are served for comparison purposes.

The research sample included undergraduate students studying at the University of Social Sciences and Humanities and the University of Science (Vietnam National University) and people working in companies or institutions in Hanoi. The undergraduate student group was assigned randomly in each class to 
complete the questionnaire after they finished their course. The employment group younger than 40 years old was assigned to complete the questionnaire after we asked their manager for the permission. Approximate time to complete the questionnaire is 20 to 25 minutes. The examiner informs the participants about the aims of the study, the expected duration of the questionnaire, and the questionnaire is confidential and voluntary.

\subsection{Measures}

In the current study, we use the following scales:

1) Sternberg's Love Scale [11]

2) Narcissistic Personality Inventory (Raskin \& Terry [6])

3) Short-form of Keyes's Mental Health Continuum [15]

The scales were translated into Vietnamese then decompiled into English to ensure the similarity between the two versions. These Vietnamese versions were then adapted on samples of Vietnamese people. Some items were eliminated to obtain the most optimal structure adapted, in our view, to Vietnamese culture. Specifically, MHC-SF including 14 items which were unchanged, with high reliability and institution of three-factor: emotional, psychological and social Well-being [17]. However, in Sternberg's 45-item Love scale, ten items were eliminated which are not clearly included in any factors. This is because of the metaphorical sayings of Vietnamese people, in which several items belonging to the intimacy factor could be understood as the presentation of a passionate factor. Besides, some authors also found that several items of Sternberg's scale should be eliminated and not explicitly included in any factors in factor analysis [18]. With 35 items left, this love scale demonstrated high reliability with a clear construct of three-factor: intimacy, passion and decision/commitment corresponding to Sternberg's theoretical framework [1]. The Vietnamese version of NPI-40 after being adapted into 20 items, demonstrated reliability and the constitution of 4 factors, and this scale can be used to measure narcissism as a personality trait on Vietnamese people [19].

In general, the eliminated items are not included in any factors (with the factor loadings are less than 0.30 ), or the eliminated items are included in two factors or more (with the factor loadings are higher than 0.30 in two factors or more). Reconsidering the elimination of many items, we found out that the statements in Vietnamese can be understood or interpreted in many different ways (for details, see [1] [19]).

\subsection{Statistical Analyses}

The present study aims to 1) examine the differences between male and female, married and unmarried groups in their level of Romantic Love, Narcissism, and Subjective Well-being; and 2) examine the correlations between Romantic Love, Narcissism, and Subjective Well-being. Therefore, the following statistical analyses are used: 
1) Confirm the Structural validity and Reliability of the Scales using Factor Analysis (the Varimax with Kaiser Normalization) and Cronbach's $\alpha$ Analysis;

2) Comparison analyses using Independent Sample T-Test, and One-way ANOVA;

3) Explore the relationship between Romantic Love, Narcissism, and Well-being using Pearson correlation.

These analyses were carried out using SPSS 20.0.

\section{Results}

Examining the correlation between narcissism, romantic love and well-being, and compare the results based on gender and marital status, we used a Pearson correlation coefficient analysis between all measures used in the study, mean scores and independent samples T-test analysis. The results are shown below:

Data from Table 1 show that the married group as compared to the unmarried group are higher in Romantic Relationship, Well-being, and lower in Narcissism in all subscales. Males have greater Romantic Love and Social Well-being results than Females.

Table 2 shows that romantic love has a positive correlation with all Well-being measures, and romantic love has the strongest correlation with Emotional Well-being.

According to Table 3, all romantic love subscales are positively related to each of the well-being subscales. In the married group, the correlations are much stronger; therefore, the romantic relationship in the married group has a higher impact on well-being, especially toward Emotional Well-being, of this cohort. As shown in Table 4.

Based on gender variable, for males, all correlations are stronger compared to females, indicating that the romantic relationship influence well-being on men was greater for women.

Table 5 shows that almost all subscales of narcissism positively correlate with Well-being, except the Exploitativeness/Entitlement trait is unrelated to Emotional Well-being. It could be explained that a higher sense of entitlement/ exploitativeness in exchange for personal benefits, people are more likely to be selfish and are not adored by others. Therefore, Entitlement/Exploitativeness is not contributing to the human' well-being.

Data from Table 6 shows that narcissism has a positive relationship with all subscales of well-being. In general, this correlation is stronger in the married group, except for the correlation between narcissism and Emotional Well-being, which lower in the married group compared to the unmarried group.

Leadership/Authority and Exploitativeness/Entitlement subscales do not correlate with Emotional Well-being in the married group. Therefore these two traits of narcissism do not have any impact on Emotional Well-being of married individuals. Exploitativeness/Entitlement does not correlate with Emotional Well-being in both married and unmarried groups and does not relate to Social Well-being in the unmarried group. 
Table 1. Mean scores comparison based on gender and marital status.

\begin{tabular}{cccccc}
\hline \multicolumn{2}{c}{ Marital status } & & & \multicolumn{2}{c}{ Gender } \\
\cline { 1 - 2 } \cline { 5 - 6 } Married & Unmarried & Mean of all participants & & Male & Female \\
\hline 7.35 & 6.42 & Intimacy & 6.87 & 7.09 & 6.77 \\
6.63 & 5.96 & Passion & 6.28 & 6.58 & 6.14 \\
7.62 & 6.17 & Commitment & 6.86 & 7.27 & 6.68 \\
7.27 & 6.20 & Romantic love & 6.71 & 7.03 & 6.57 \\
3.06 & 3.60 & Leadership/Authority & 3.34 & 3.51 & 3.27 \\
2.93 & 3.30 & Superiority/Arrogance & 3.12 & 3.04 & 3.16 \\
4.18 & 4.36 & Self-absorption/Self-admiration & 4.28 & 4.29 & 4.27 \\
4.23 & 4.67 & Exploitativeness/Entitlement & 4.46 & 4.43 & 4.48 \\
3.54 & 3.93 & Narcissism & 3.74 & 3.77 & 3.73 \\
4.40 & 4.09 & Emotional Well-being & 4.23 & 4.27 & 4.21 \\
3.72 & 3.47 & Social Well-being & 3.58 & 3.77 & 3.49 \\
4.33 & 4.10 & Psychological Well-being & 4.21 & 4.28 & 4.18 \\
4.13 & 3.87 & Well-being & 3.99 & 4.10 & 3.94 \\
\hline 3
\end{tabular}

Note: Bold and italic numbers: higher statistically significant with $\mathrm{p}<0.01$ or $\mathrm{p}<0.05$ in Independent Samples T-test analysis.

Table 2. Correlation between all measures of Romantic Love and Well-being.

\begin{tabular}{ccccc}
\hline & Intimacy & Commitment & Passion & Romantic Love \\
\hline Emotional Well-being & $0.330^{\star *}$ & $0.262^{* *}$ & $0.273^{\star *}$ & $0.309^{* *}$ \\
Social Well-being & $0.175^{\star *}$ & $0.164^{\star *}$ & $0.210^{\star *}$ & $0.194^{\star *}$ \\
Psychological Well-being & $0.246^{\star *}$ & $0.204^{\star *}$ & $0.207^{\star *}$ & $0.235^{\star *}$ \\
Well-being & $0.277^{\star *}$ & $0.235^{* *}$ & $0.259^{\star *}$ & $0.275^{\star *}$ \\
\hline
\end{tabular}

Note: ${ }^{*}$ statistically significant correlation with $\mathrm{p}<0.01,{ }^{*}$ statistically significant correlation with $\mathrm{p}<0.05$.

Table 3. Correlation between components of Romantic Love and Well-being among the married and unmarried group.

\begin{tabular}{|c|c|c|c|c|c|}
\hline & Marital Status & Intimacy & Commitment & Passion & Romantic Love \\
\hline \multirow{2}{*}{ Emotional Well-being } & Married group & $0.434^{\star \star}$ & $0.348^{\star *}$ & $0.408^{\star *}$ & $0.419^{* *}$ \\
\hline & Unmarried group & $0.185^{\star *}$ & $0.142^{*}$ & 0.105 & $0.161^{\star}$ \\
\hline \multirow{2}{*}{ Social Well-being } & Married group & $0.173^{\star *}$ & $0.165^{\star}$ & $0.255^{\star *}$ & $0.206^{\star *}$ \\
\hline & Unmarried group & $0.129^{*}$ & 0.123 & $0.141^{\star}$ & $0.143^{\star}$ \\
\hline \multirow{2}{*}{$\begin{array}{c}\text { Psychological } \\
\text { Well-being }\end{array}$} & Married group & $0.263^{* *}$ & $0.256^{\star *}$ & $0.266^{\star *}$ & $0.279^{* *}$ \\
\hline & Unmarried group & $0.183^{\star *}$ & 0.118 & 0.119 & $0.151^{\star}$ \\
\hline \multirow{2}{*}{ Well-being } & Married group & $0.312^{\star *}$ & $0.282^{\star *}$ & $0.343^{\star *}$ & $0.330^{* *}$ \\
\hline & Unmarried group & $0.190^{\star *}$ & $0.146^{*}$ & $0.143^{\star}$ & $0.175^{\star *}$ \\
\hline
\end{tabular}


Table 4. Correlation between Well-being and Romantic Love among Males and Females.

\begin{tabular}{cccccc}
\hline & Gender & Intimacy & Commitment & Passion & Romantic Love \\
\hline \multirow{2}{*}{ Emotional Well-being } & Male & $0.357^{* *}$ & $0.289^{* *}$ & $0.280^{* *}$ & $0.328^{* *}$ \\
& Female & $0.322^{* *}$ & $0.251^{* *}$ & $0.271^{* *}$ & $0.302^{* *}$ \\
\multirow{2}{*}{ Social Well-being } & Male & $0.198^{*}$ & $0.192^{*}$ & $0.231^{* *}$ & $0.218^{* *}$ \\
& Female & $0.157^{* *}$ & $0.135^{*}$ & $0.185^{* *}$ & $0.168^{* *}$ \\
\multirow{2}{*}{ Psychological Well-being } & Male & $0.283^{* *}$ & $0.233^{* *}$ & $0.216^{* *}$ & $0.261^{* *}$ \\
& Female & $0.232^{* *}$ & $0.186^{* *}$ & $0.195^{* *}$ & $0.220^{* *}$ \\
Well-being & Male & $0.309^{* *}$ & $0.266^{* *}$ & $0.275^{* *}$ & $0.300^{* *}$ \\
& Female & $0.261^{* *}$ & $0.211^{* *}$ & $0.242^{* *}$ & $0.255^{* *}$ \\
\hline
\end{tabular}

Table 5. Correlation between all measures of Narcissism and Well-being.

\begin{tabular}{cccccc}
\hline & Leadership/Authority & Superiority/Arrogance & $\begin{array}{c}\text { Self-absorption/ } \\
\text { Self-admiration }\end{array}$ & Exploitativeness/Entitlement & Narcissism \\
\hline Emotional Well-being & $0.101^{*}$ & $0.111^{* *}$ & $0.228^{* *}$ & 0.023 & $0.143^{* *}$ \\
Social Well-being & $0.289^{* *}$ & $0.251^{* *}$ & $0.237^{* *}$ & $0.095^{*}$ & $0.289^{* *}$ \\
Psychological Well-being & $0.248^{* *}$ & $0.185^{* *}$ & $0.397^{* *}$ & $0.140^{* *}$ & $0.301^{* *}$ \\
Well-being & $0.268^{* *}$ & $0.226^{* *}$ & $0.346^{* *}$ & $0.112^{* *}$ & $0.304^{* *}$ \\
\hline
\end{tabular}

Table 6. Correlation between Narcissism and Well-being based on marital status.

\begin{tabular}{ccccccc}
\hline & Marital Status & Leadership/Authority & Superiority/Arrogance & $\begin{array}{c}\text { Self-absorption/ } \\
\text { Self-admiration }\end{array}$ & Exploitativeness/Entitlement & Narcissism \\
\hline Emotional & Married group & 0.080 & $0.157^{*}$ & $0.189^{* *}$ & -0.008 & $0.131^{*}$ \\
Well-being & Unmarried group & $0.189^{* *}$ & $0.126^{*}$ & $0.294^{* *}$ & 0.111 & $0.228^{* *}$ \\
Social & Married group & $0.364^{* *}$ & $0.299^{* *}$ & $0.297^{* *}$ & $0.142^{*}$ & $0.359^{* *}$ \\
Well-being & Unmarried group & $0.285^{* *}$ & $0.258^{* *}$ & $0.203^{* *}$ & 0.106 & $0.290^{* *}$ \\
Psychological & Married group & $0.296^{* *}$ & $0.244^{* *}$ & $0.435^{* *}$ & $0.234^{* *}$ & $0.369^{* *}$ \\
Well-being & Unmarried group & $0.273^{* *}$ & $0.186^{* *}$ & $0.396^{* *}$ & $0.125^{*}$ & $0.315^{* *}$ \\
& Married group & $0.319^{* *}$ & $0.287^{* *}$ & $0.378^{* *}$ & $0.166^{* *}$ & $0.362^{* *}$ \\
Well-being & Unmarried group & $0.301^{* *}$ & $0.233^{* *}$ & $0.352^{* *}$ & $0.134^{*}$ & $0.334^{* *}$ \\
\hline
\end{tabular}

Table 7 shows that Leadership/Authority and Self-absorption/Self-admiration traits are negatively correlated with Intimacy, Commitment, and Romantic Love. The exception is that Superiority/Arrogance has a positive relationship with Romantic Love.

Table 8 shows that in general, both married and unmarried groups, romantic love and narcissism are unrelated to each other. However, the Self-absorption/ Self-admiration trait in Narcissism and Narcissism have a positive correlation with Passion subscale in Romantic love; the Superiority/Arrogance trait is positively related to Romantic love subscales (furthermore, the association is stronger in the unmarried groups).

Interestingly, there is different between men and women in Romantic LoveNarcissism correlation. 
Table 7. Correlation between all measures of Narcissism and Romantic Love.

\begin{tabular}{ccccc}
\hline & Intimacy & Commitment & Passion & Romantic Love \\
\hline Leadership/Authority & $-0.090^{*}$ & -0.062 & 0.035 & -0.050 \\
Superiority/Arrogance & $-0.110^{*}$ & -0.066 & $0.120^{* *}$ & -0.036 \\
Self-absorption/Self-admiration & $0.133^{* *}$ & $0.160^{\star *}$ & $0.120^{* *}$ & $0.154^{\star *}$ \\
Exploitativeness/Entitlement & -0.044 & -0.014 & 0.052 & -0.007 \\
Narcissism & -0.052 & -0.011 & $0.097^{\star}$ & 0.003 \\
\hline
\end{tabular}

Table 8. Correlation between Narcissism and Romantic Love (Based on marital status).

\begin{tabular}{|c|c|c|c|c|c|}
\hline & Marital Status & Intimacy & Commitment & Passion & Romantic Love \\
\hline \multirow{2}{*}{ Leadership/Authority } & Married group & -0.062 & -0.020 & 0.062 & -0.011 \\
\hline & Unmarried group & -0.008 & 0.029 & 0.085 & 0.034 \\
\hline \multirow{2}{*}{ Superiority/Arrogance } & Married group & -0.061 & -0.049 & $0.143^{*}$ & 0.001 \\
\hline & Unmarried group & -0.062 & 0.017 & $0.170^{* *}$ & 0.033 \\
\hline \multirow{2}{*}{ Self-absorption/Self-admiration } & Married group & 0.120 & $0.191^{* *}$ & $0.150^{*}$ & $0.169^{* *}$ \\
\hline & Unmarried group & $0.205^{\star *}$ & $0.221^{* *}$ & $0.127^{*}$ & $0.214^{* *}$ \\
\hline \multirow{2}{*}{ Exploitativeness/Entitlement } & Married group & 0.005 & 0.094 & 0.092 & 0.070 \\
\hline & Unmarried group & 0.017 & 0.026 & 0.086 & 0.042 \\
\hline \multirow{2}{*}{ Narcissism } & Married group & -0.014 & 0.047 & $0.132^{*}$ & 0.055 \\
\hline & Unmarried group & 0.031 & 0.080 & $0.147^{\star}$ & 0.090 \\
\hline
\end{tabular}

Data from Table 9 shows that Leadership/Authority and Self-absorption/Selfadmiration traits in men are negatively related to romantic love (the correlation is not found in women). However, in women, the Superiority/Arrogance trait has a positive relationship with Romantic love; Self-absorption/Self-admiration and Narcissism have a positive correlation with Passion in Romantic Love (the correlation is not found in women). Table 9 also shows that Leadership/Authority and Self-absorption/Self-admiration in men have a negative relationship with Romantic love, while the Superiority/Arrogance trait in women has a positive correlation with Romantic Love. Superiority/Arrogance trait in males and Exploitativeness/Entitlement trait in men and women do not correlate with any Romantic Love subscales. In short, narcissism is not associated with Romantic Love.

Therefore, the relationship between romantic love, narcissism, and well-being presented in our first hypothesis has not been verified. As shown in Table 10.

However, our study shows that both narcissism (self-love) and romantic relationship (love of someone else) are positively related to well-being, Yet the two different forms of love are independent and do not correlate with each other.

Using a Simple Linear Regression Analysis to examine the possibility that romantic love and narcissism could predict well-being, results show that romantic love can predict $7.6 \%$ and narcissism can predict $9.2 \%$ coefficient of well-being. 
Table 9. Correlation between Narcissism and Romantic Love (Based on Gender).

\begin{tabular}{cccccc}
\hline & Gender & Intimacy & Commitment & Passion & Romantic Love \\
\hline \multirow{2}{*}{ Leadership/Authority } & Male & $-0.189^{*}$ & $-0.159^{*}$ & -0.099 & $-0.165^{*}$ \\
& Female & -0.054 & -0.042 & 0.083 & -0.016 \\
Superiority/Arrogance & Male & $-0.222^{* *}$ & $-0.243^{* *}$ & -0.001 & $-0.189^{*}$ \\
& Female & -0.021 & 0.034 & $0.202^{* *}$ & 0.064 \\
Self-absorption/Self-admiration & Male & 0.089 & 0.092 & 0.068 & 0.091 \\
& Female & $0.153^{* *}$ & $0.186^{* *}$ & $0.142^{*}$ & $0.180^{* *}$ \\
& Male & -0.088 & -0.080 & 0.005 & -0.066 \\
Exploitativeness/Entitlement & Female & -0.018 & 0.012 & 0.075 & 0.020 \\
& Male & -0.152 & -0.145 & -0.023 & -0.125 \\
& Female & 0.005 & 0.044 & $0.155^{* *}$ & 0.065 \\
\hline
\end{tabular}

Table 10. Correlation between Narcissism, Romantic Love, and Well-being.

\begin{tabular}{ccc}
\hline & Narcissism & Well-being \\
\hline Romantic love & 0.003 & $0.275^{* *}$ \\
Narcissism & & $0.304^{* *}$ \\
\hline
\end{tabular}

Table 11. Predictability of love and narcissism for subjective well being.

\begin{tabular}{cccccccccc}
\hline Independent variables & $\mathrm{R}^{2}$ & $\mathrm{R}^{2} \Delta$ & $\mathrm{F}$ & \multicolumn{2}{c}{$\begin{array}{c}\text { Unstandardized } \\
\text { Coefficients }\end{array}$} & \multicolumn{2}{c}{$\begin{array}{c}\text { Standardized } \\
\text { coefficients }\end{array}$} \\
\cline { 5 - 9 } & & & & & $\mathrm{B}$ & $\mathrm{SE}$ & $\beta$ & $\mathrm{p}$ \\
\hline Romantic love & 0.076 & 0.074 & 390.95 & 0.150 & 0.024 & 0.275 & 0.000 \\
Narcissism & 0.092 & 0.091 & 540.44 & 0.273 & 0.037 & 0.304 & 0.000 \\
Romantic love and Narcissism & 0.167 & 0.163 & 480.37 & 0.150 & 0.023 & 0.276 & 0.000 \\
& & & & 0.267 & 0.037 & 0.298 & 0.000 \\
\hline
\end{tabular}

Dependent variable: Well-being.

Table 11 shows that both romantic love and narcissism can predict $16.7 \%$ of the coefficient of well-being. The percentages are different based on gender and marital status.

\section{Discussions and Conclusion}

\subsection{The Relationship between Narcissism and Well-Being}

We first assume that in a collectivistic society like Vietnam, where it is said that the majority criticizes individualism, selfishness, arrogance, entitlement, narcissism may have a negative impact toward Well-being. However, contrary to our assumption, the results showed that narcissism is positively correlated with Well-being among Vietnamese subjects. This is similar to several studies results obtained in Western cultures [3] [20] [21].

The present research was undertaken in Hanoi, the second largest city and 
capital of Vietnam. We would suggest that in the context of development and international integration today, collectivistic and individualistic perspectives of Vietnamese people have been changing dramatically, especially in urban areas. Economic developmental pressure and harsh competition in the labor market make every organization and individual prioritize individualism, uniqueness, active endeavor, and creativity with creative ideas being more welcomed in many areas in the city. Linking this with previous arguments, narcissism may have a positive impact on social activities, help individuals easily express themselves and participate in many social relationships, hence make people feel happier [20] [21].

Besides, we also agree with several researchers that narcissists tend to evaluate themselves more positively, and are more satisfied with their lives and social environment; therefore narcissists have higher well-being [3]. Narcissists with self-love behave in a more self-respectful way, for instance, caring for physical appearance (included body-image and clothing), encouraging themselves mentally, having self-efficacy and autonomy.

Entitlement, which is often considered as a negative trait in Vietnam, is also shown to make subjects feel happier. Why? Vietnamese have many idioms which encourage people to live according to social norms, with sufferance and resignation (for instance, "một điều nhịn, chin điều lành"; "dĩ hòa vi quý")—the living philosophy itself in many cases makes people suffer injustice, infringe family life and that in the workplace, and in the public sphere. This philosophy of life also develops resignation, diminishes competitiveness, personal opinions, and political views amongst Vietnamese people. Resignation develops displeased individuals who are unable to compete directly, producing anti-social behavior to relieve stress. Resigned to injustice and infringed upon, culminate in an unbearable status that results in anger (for instance, the idiom "con giun xéo mãi cũng oằn"). The "Resignation-unbearable-anger" pattern often occurs in many situations in Vietnamese families and social relationships. All of the emotions and behavior like "resignation," "displeasure," "do not dare to argue face-toface," "be bad-mouth," "anger due to the unbearable" leads to stressful thinking, negatively affecting individual well-being. Therefore, a reasonable and outspoken serve of entitlement in order to avoid displeasure somehow helps individuals sustain positive emotions and behavior, thereby promoting well-being.

Our result suggests that accepting, with a serve of resignation, unreasonable things until they reach an unbearable point results in angry destruction everything with anger. Things should be kept reasonable from the beginning to protect ourselves as well as our family and the nation, to avoid personal and group conflicts, to avoid anger and unwanted war after long-term resignation.

The results of the present study suggest that we should improve some of the traits of narcissism in Vietnamese society, for instance, self-respect, self-efficacy, a high serve of self-evaluation, autonomy, and a reasonable serve of entitlement.

However, it needs to be emphasized that the participants of the present study have narcissism mean scores of 3.74 (in 7-point Likert scale) which is rather low, 
the correlation between narcissism and well-being may be confined only in a certain range and may be an uncorrelation might occurs if narcissism mean scores are above this average (for instance, from 5 to 7 ). Entitlement may also lead to negative impact if it becomes extreme.

\subsection{The Relationship between the Romantic Love and Well-Being}

Romantic love has the significant positive correlation to Well-being. Many studies from other countries also reached similar conclusions [22] [23]. There are many ways of interpreting these results.

After a number of studies, Diener et al. concluded that people with higher levels of Well-being get married and accept married life afterward more easily [12]. So the question is: Do happy people get married more easily and continue being happy afterward or do they become happier because of their marriage? Further studies are required to explore this correlation. According to our study, people with marital status are happier than those who are not. By way of explanation, we suppose this result comes from the importance of family life in Vietnamese cultural rituality, in which it is said that getting into marriage is inevitable principle when one reaches adulthood (as in Vietnamese idiom "Trai khôn dựng vợ, gái lớn gả chông" - "Boy emerging to adulthood find his wife, girls emerging to adulthood get married her husband"). According to another popular idiom "good shelter, good career", it is implicitly shown that adults should have a family which provided a good, safe and happy shelter. This will facilitate achieving a successful career. If any adult is still single, then everyone around him/her (including his/her family, relatives, neighbors, and colleagues as well) could keep their concerns as when she/he gets married, or they will become matchmakers who try to find the suitable person to recommend to him/her. Thus, it is claimed that individuals who are in a marriage state are more peaceful and have more social acceptance as well as mental support from his/her community, which is facilitated them to become happier.

The romantic love of individuals in the marriage relationship is backed up by laws and encompassing higher commitment than romantic love without marriage. Also, marital relationship means they have had a long-term and stable love relationship with their partners, and they also have more profound bondedness to each other as well as to their own children. Therefore, individuals in marriage have their romantic love with the stronger level of three components, and their romantic love is strongly correlated with well-being compared to the single individuals.

\subsection{The Relationship between Narcissism and Romantic Love}

Our first assumptions suggest that narcissism and romantic relationship have a negative association with each other. Given this assumptions, Leadership/ Authority and Self-absorption/Self-admiration traits in men have a negative association with romantic love. However, in general, narcissism does not correlate with romantic love. The assumptions that a selfish and self-loving person will be 
less likely to enter into a romantic relationship is invalid. On the contrary, some of the narcissism components in females are positively associated with some of the romantic love components. Our results show that even if women love themselves, it does not negatively affect how they love another person. Two forms of love in women are not associated with each other and, somehow, they even support each other. It is legitimate to say that self-love is as important as loving another person. This study suggests that if one appreciates oneself; then he/she will know how to love and appreciate others.

In conclusion, the hypothesis that romantic love is positively correlated with well-being has been confirmed by the study results. However, the others hypotheses have been rejected. The study results indicate a positive correlation between narcissism and well-being; on the other hand, there is no significant correlation between well-being and romantic love.

\section{Limitations of the Study}

Firstly, the study sample is not representative of the population; participants are undergraduate students and people working in Hanoi. Adults who are not enrolling in higher education, unemployed adults, and people living and working in rural areas are not recruited in the study.

Secondly, the elimination of many items in romantic love and narcissism' scale indicates cross-cultural invalidity of the scales within Vietnamese culture. It is essential to develop measurements of romantic love and narcissism which fits the culture of Asia, especially Vietnamese culture.

\section{Acknowledgements}

This research is funded by Vietnam National Foundation for Science and Technology Development (NAFOSTED) under grant number 501.01-2016.02

\section{Conflicts of Interest}

The authors declare no conflicts of interest regarding the publication of this paper.

\section{References}

[1] Truong T.K.H. and Nguyen T.H.G. (2016) Nghiên cứu tình yêu đôi lứa bằng thang đo của Stenberg. Tap chí Tâm lý hoc, Viện hàn lâm Khoa học Xã hội Việt nam, 11, 20-30.

[2] Gebauer, J.E., Sedikides, C., Verplanken, B. and Maio, G.R. (2012) Communal Narcissism. Journal of Personality and Social Psychology, 103, 854-878. https://doi.org/10.1037/a0029629

[3] Zemojtel-Piotrowska, M., Clinton, A. and Piotrowski, J. (2014) Agentic and Communal Narcissism and Subjective Well-Being: Are Narcissistic Individuals Unhappy? A Research Report. Current Issues in Personality Psychology, 2, 10-16. https://doi.org/10.5114/cipp.2014.43097

[4] Pincus, A.L. and Lukowitsky, M.R. (2010) Pathological Narcissism and Narcissistic Personality Disorder. Annual Review of Clinical Psychology, 6, 421-446. https://doi.org/10.1146/annurev.clinpsy.121208.131215 
[5] Emmons, R.A. (1984) Factor Analysis and Construct Validity of the Narcissistic Personality Inventory. Journal of Personality Assessment, 48, 291-300. https://doi.org/10.1207/s15327752jpa4803_11

[6] Raskin, R. and Terry, H. (1988) A Principal-Components Analysis of the Narcissistic Personality Inventory and Further Evidence of Its Construct Validity. Journal of Personality and Social Psychology, 54, 890-902. https://doi.org/10.1037/0022-3514.54.5.890

[7] Rubin, Z. (1970) Measurement of Romantic Love. Journal of Personality and Social Psychology, 16, 265-273. https://doi.org/10.1037/h0029841

[8] Lee, J.A. (1977) A Typology of Styles of Loving. Personality and Social Psychology Bulletin, 3, 173-182. https://doi.org/10.1177/014616727700300204

[9] Sternberg, R. (1986) The Triangular Theory of Love. Psychological Review, 93, 119-135. https://doi.org/10.1037/0033-295X.93.2.119

[10] Aron, A. and Henkemeyer, L. (1995) Marital Satisfaction and Passionate Love. Journal of Social and Personal Relationship, 12, 139-146.

https://doi.org/10.1177/0265407595121010

[11] Sternberg, R. (1997) Construct Validation of a Triangular Love Scale. European Journal of Social Psychology, 27, 313-335. https://doi.org/10.1002/(SICI)1099-0992(199705)27:3<313::AID-EJSP824>3.0.CO;2-4

[12] Diener, E., Emmons, R.A., Larsen, R.J. and Griffin, S. (1985) The Satisfaction with Life Scale. Journal of Personality Assessment, 49, 71-75. https://doi.org/10.1207/s15327752jpa4901_13

[13] Ryff, C.D. (1989) Happiness Is Everything, or Is It? Explorations on the Meaning of Psychological Well-Being. Journal of Personality and Social Psychology, 57, 1069-1081. https://doi.org/10.1037/0022-3514.57.6.1069

[14] Keyes, C.L.M. (1998) Social Well-Being. Social Psychology Quarterly, 61, 121-140. https://doi.org/10.2307/2787065

[15] Keyes, C.L.M. (2002) The Mental Health Continuum: From Languishing to Flourishing in Life. Journal of Health and Social Behavior, 43, 207-222. https://doi.org/10.2307/3090197

[16] Ryff, C.D. and Keyes, C.L.M. (1995) The Structure of Psychological Well-Being Revisited. Journal of Personality and Social Psychology, 69, 719-727. https://doi.org/10.1037/0022-3514.69.4.719

[17] Truong T.K.H. (2015) Cảm nhận hạnh phúc chủ quan của người trưởng thành. Tap chí Tâm lý học, Viện hàn lâm Khoa học Xã hội Việt nam, 11, 34-48.

[18] Hatfield, E. and Sprecher, S. (1986) Measuring Passionate Love in Intimate Relationships. Journal of Adolescence, 9, 383-410. https://doi.org/10.1016/S0140-1971(86)80043-4

[19] Truong T.K.H. (2017) Tìm hiểu về tính ái kỷ và thang đo nhân cách ái kỷ. Tap chí Tâm lý họ, Viện hàn lâm Khoa học Xã hội Việt nam, 9, 38-48.

[20] Sedikides, C., Rudich, E., Gregg, A., Kumashiro, M. and Rusbult, C. (2004) Are Normal Narcissists Psychologically Healthy? Self-Esteem Matters. Journal of Personality and Social Psychology, 87, 400-416. https://doi.org/10.1037/0022-3514.87.3.400

[21] Campbell, W.K., Bush, C.P., Brunell, A.B. and Shelton, J. (2005) Understanding the Social Costs of Narcissism: The Case of the Tragedy of the Commons. Personality and Social Psychology Bulletin, 31, 1358-1368.

https://doi.org/10.1177/0146167205274855 
[22] Myers, D.G. (1999) Close Relationships and Quality of Life. In: Kahneman, D., Diener, E. and Schwarz, N., Eds., Well-Being: The Foundations of Hedonic Psychology, Russell Sage Foundation, New York, 374-391.

[23] Acevedo, B.P. and Aron, A. (2009) Does a Long-Term Relationship Kill Romantic Love. Review of General Psychology, 13, 59-65. https://doi.org/10.1037/a0014226 